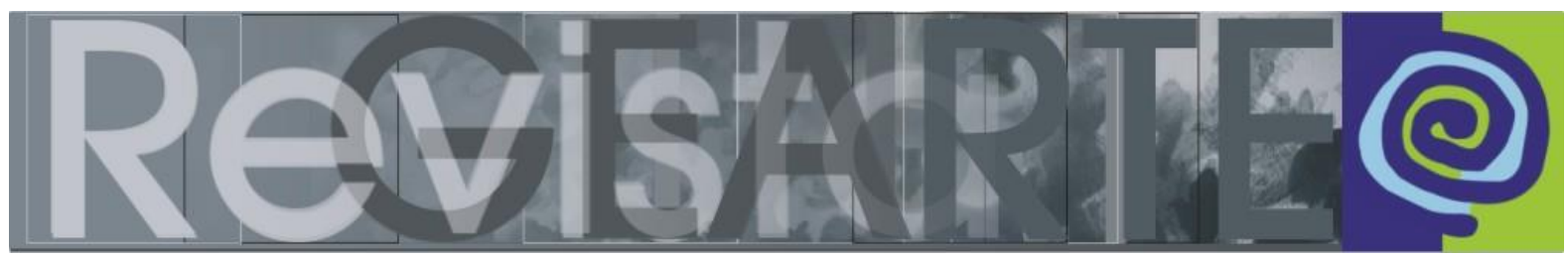

e-ISSN 2357-9854

\title{
Entre Rios Grandes, encontros estéticos significantes
}

\author{
Gilvânia Maurício Dias de Pontes \\ (Universidade Federal do Rio Grande do Norte — UFRN, Natal/RN, Brasil)
}

\begin{abstract}
RESUMO - Entre Rios Grandes, encontros estéticos significantes - Este texto trata de encontros, afetos, estesia e estética que produzem (auto) formação, na relação entre o Grupo de Pesquisa em Educação e Arte da UFRGS e o trabalho de formação docente na UFRN. Refere-se, também, a interfaces entre referenciais e contextos diversos na investigação de processos de significação para o ensino de arte na infância.
\end{abstract}

PALAVRAS-CHAVE

Pesquisa. Formação docente. Estética. Educação infantil. Ensino de artes visuais.

ABSTRACT - Between two "Rios Grandes", meaninful aesthetic encounters - This text deals with encounters, affections, esthesia and aesthetics that produce (in) formation, in the relationship between the Group of Research in Education and Art of UFRGS and the work of teacher training at UFRN. It also refers to interfaces between references and contexts in the investigation of meaning processes for the teaching of art in childhood.

KEYWORDS

Research. Training. Aesthetics. Early childhood education. Teaching of visual arts

\section{Introdução}

O que nos liga ao outro a ponto de nos transformar? Talvez seja essa a questão disparadora das reflexões sobre os ecos de um grupo de pesquisa em processos pessoais/coletivos de formação docente. Assim, composto por complexos movimentos, que não cabem na escrita de um artigo, se instaura o desafio de comunicar o vivido na relação com o GEARTE - Grupo de Pesquisa em Educação e Arte da UFRGS. O GEARTE é um grupo interinstitucional que agrega pesquisadores de várias universidades e dialoga com as áreas da cultura visual, semiótica discursiva, estética, história, teoria e crítica da arte. As andanças pelos espaços formativos do GEARTE, as marcas impressas da história do grupo e as marcas construídas por mim em mim, na interação com o grupo, ampliaram o meu olhar sobre o campo da Arte e da Educação, o que possibilitou diversificar as relações que estabelecia com o tema dos saberes e práticas da dimensão estética na formação de professores da infância. Mas, esse processo não pode ser explicitado somente em formalidades acadêmicas e profissionais, nesse texto, o título faz referência a dois rios grandes, o Rio do Norte 
e o Rio do Sul. Os rios são líquidos em sua materialidade, mas, também gasosos, o que faz com que sua composição contenha caminhos, percursos e movimentos em transformação. Rios são culturais, navegar demanda encarar o medo e assumir o risco. Fazer esforço, modificar-se e contar para outros que houve um trajeto modificante, como muitas vidas se encontrando, dialogando para criar práticas de olhar e estar em Arte e Educação.

O GEARTE agrega pesquisadores, diz os textos de sua apresentação nos materiais de divulgação e página da internet. $\mathrm{Na}$ busca de significados para ação que se faz em verbo no agregar gearteano, encontra-se a (com) vivência, a (re)união e a associação que significa soma na diversidade de pesquisadores e temáticas que por ali se fazem presentes. Diversidade que ora se apresenta líquida e visível em suas correntes, ora se presentifica gasosa, invisível, mas perceptível em suas influências. Convivência pautada pelo diálogo e respeito ao outro. O que une seus pesquisadores são interesses comuns pela Arte e pela Educação, mas as trajetórias são próprias e os percursos criativos são diferenciados. No GEARTE, não se faz obrigatório pensar igual ou professar o mesmo credo. Nesse grupo há o acolhimento ao pesquisador em suas peculiaridades, o lugar de fala é garantido como metodologia de formação de autoria criativa. Como nos diz Merleau-Ponty (2012, p. 48) em A prosa do mundo: "a linguagem, no seu estado nascente e vivo, é o gesto de retomada e recuperação que reúne a mim mesmo e aos outros". Gesto que produz ecos, e se transforma ao transformar o sujeito de linguagem; para retornar ao mundo como expressão. Assim, na prática dialógica assumida pelo GEARTE, muitos são reunidos e os ecos propagados por diferentes universidades transformados em expressão em diferentes trabalhos de pesquisa e formação.

\section{Aproximações}

As Artes Visuais, enquanto linguagens - formas de expressão e comunicação estruturante do sujeito no mundo - fazem parte do cotidiano das crianças e, como tal das práticas docentes destinadas à infância. Mas, nem sempre as especificidades das linguagens artísticas são consideradas com intencionalidade necessária para que se 
promova o acesso das crianças ao conhecimento já construído nessa área, de forma significativa que amplie o seu repertório de leitura e expressão nessas linguagens. Autoras como Barbosa (2009; 2015), Pillar (1997; 2002; 2012). lavelberg (2006; 2013); Richter (2005) e Rossi (3003), entre outros, têm alertado para a importância de considerar o desenvolvimento dos processos dos processos expressivos das crianças em linguagens artísticas quando da proposição de experiências de ensino/aprendizagem. Na produção dessas autoras encontramos reflexões sobre a participação dos professores como mediadores do acesso das crianças às linguagens da Arte.

Barbosa (2009), ao tratar da importância das imagens de arte na educação, afirma que o resgate do conhecimento de arte pode ocorrer através do contato/diálogo das crianças com as imagens. A imagem é algo a ser lido e que pode fazer parte do cotidiano das crianças na escola com vistas a uma alfabetização visual e estética. Abordar Arte sem que se ponha à disposição das crianças a imagem é como querer alfabetizar para a leitura e escrita sem colocar as crianças em contato com livros.

O professor é figura fundamental na apresentação do repertório cultural da Arte para as crianças, por isso a urgência da proposição de situações de formação docente que tematizem o trabalho com as linguagens artísticas na infância. Mas, mesmo que o professor tenha tido acesso aos referenciais contemporâneos que tratam de Arte/Educação, há ainda um percurso a construir entre estes e as práticas docentes, pois a produção de mediações é um processo que envolve outras relações pertinentes à formação de professores e aos contextos em que estas ocorrem.

Em pesquisa anterior à inserção no GEARTE (PONTES, 2001), eu estivera atenta aos movimentos que constituem as práticas docentes para o ensino das artes na Educação Infantil, observando a produção de sentido dos professores no que diz respeito às intenções que orientam as suas ações. Através do levantamento de situações de presença da arte, nos relatos escritos de professores de uma instituição pública de Educação Infantil, foi possível identificar que os professores, conscientemente ou não, haviam mediado situações de contanto das crianças com as 
linguagens das artes. Estava, portanto, diante de dimensões da presença da arte na educação infantil em que a área aparecia como linguagem essencial à expressão e comunicação infantil e como um repertório de conhecimentos construídos culturalmente e ao qual a criança pode ter acesso através das ações intencionais dos professores. Essa constatação exigia que o fluxo da pesquisa observasse o cotidiano da educação infantil no qual são gestadas as práticas docentes. A observação da trama de organização de práticas docentes, tendo o cotidiano da educação infantil como referência, conduziu-me à consideração das interfaces ente a área de Arte, as especificidades das infâncias e a organização curricular que influencia nas situações de mediação no ensino/aprendizagem das linguagens artísticas. Desta maneira, a pesquisa passou a carecer de um olhar transdisciplinar em que os constructos da Arte e da Pedagogia estivessem presentes quando da tessitura das relações para tratar das situações educativas de arte para crianças.

A opção pela pesquisa inserida no cotidiano da Educação Infantil e pela abordagem de práticas em movimento requer a observação do processo de construção de práticas, e não somente a consideração do produto final. Assim, é preciso focar no movimento que produz a prática identificando as intencionalidades que o constitui. Nesse intento, a noção de conhecimento que norteia o olhar sobre a docência e sobre a pesquisa diz respeito ao processo de apreensão racional do real, para perceber o que produz o movimento. No entanto, essa busca pela racionalidade que organiza as práticas esteve permeada por sensibilidade, visto que não é possível separar sensível e inteligível na produção do conhecimento.

Contemporaneamente, o pesquisador se vê diante da necessidade de leitura/acompanhamento dos processos de subjetivação envolvidos na investigação, que são complexos e não podem ser entendidos segundo uma verdade objetiva, simplificada e generalizável. Assim, a aproximação a uma realidade complexa requer olhares plurais e implica uma abordagem que não separe sujeito-objeto, naturezacultura, objetivo-subjetivo, teoria-prática, pesquisador-pesquisado; implica, sobretudo, a construção de outra postura, de um modo de operar com/sobre as práticas que considere a pluralidade e a mutabilidade das experiências. 
A quem questionar sobre a organização de práticas? O desafio de produção de respostas para essa questão, que é reflexo da opção metodológica pela investigação das práticas educativas em movimento, encontraria ecos no trabalho do GEARTE, e fundamentaria a futuras pesquisas. Os estudos sobre a produção de sentido na abordagem da Semiótica Discursiva, um dos aportes teóricos e metodológicos do GEARTE, remete à produção de sentido sentido - apreensão sensível e produção de significação- a partir da interação, leitura e análise de textos e práticas. Fundamentada, também, pela fenomenologia, a Semiótica Discursiva contemporânea considera que o mundo se apresenta como uma totalidade que faz sentido. É do nosso estar-no-mundo como leitores que nasce a possibilidade de sentidos. A leitura acaba por adquirir o estatuto de uma prática em que quem lê não o faz distanciado daquilo que norteia o seu agir no mundo; não somente o sentido do texto se constrói, mas o próprio ato de leitura.

A análise de relato de práticas de professores da Educação Infantil, para analisar o movimento que produz práticas, apontou para a relação entre as vivências estéticas e artísticas das crianças e o desenvolvimento das possibilidades de leitura e crianças em linguagens artísticas.

O desejo de realizar estudos sobre a dimensão estética nas práticas e formação de professores das infâncias se delineou quando da minha participação no Paideia/UFRN - um dos três centros de formação continuada para professores de Arte e Educação Física da Rede Nacional de Formação Continuada para professores da Educação Básica $/ \mathrm{MEC}^{21}$. Participei da elaboração do projeto para concorrer ao edital do MEC para seleção de propostas e criação dos centros; depois da seleção fiz parte da equipe de estruturação do centro; do planejamento dos cursos, especialmente do Curso de Ensino de Arte e Educação Física na Infância; da

21 Edital 001/MEC/SEF, lançado no final de 2003, convoca instituições de ensino superior, públicas e comunitárias, a formular projetos de formação continuada para professores da Educação Básica, para criação da Rede Nacional de Formação Continuada para Professores para Educação Básica. A Rede tinha como objetivo a oferta e desenvolvimento de programas de formação permanente, visando melhorar a qualidade do ensino e do aprendizado dos alunos por meio da participação dos docentes em processos de formação continuada. 
produção de materiais para o curso destinado à infância e outros cursos; atuei como professora no Curso de Ensino de Arte e Educação Física na Infância, ministrando o módulo de Arte e infância. O trabalho de formação desse centro, de 2004 a 2009, se estendeu por vários municípios do RN e por estados das regiões Norte e Nordeste do país. Como equipe de formação, buscávamos a produção de situações de formação que considerassem os professores como sujeitos de seus aprendizados, isto é, a práxis do professor foi tomada como ponto de partida, de constituição das ações de formação. Eu observava os meandros da dimensão estética presente na organização da atuação docente. As experiências estéticas e artísticas dos professores marcavam as suas práticas e as formas de interpretação do seu fazer.

As experiências de pesquisa, de docência e formação de professores evidenciaram que a prática docente dos professores de infância, quando propõem situações de aprendizagem nas linguagens artísticas às crianças, traz subjacentes concepções, conscientes ou não, sobre estética, arte, ensino e infância. Essa constatação incitou a minha curiosidade pela investigação da dimensão estética da docência e da formação do professor. A tese de que as experiências estéticas dos professores, ocorridas em diferentes instâncias sociais, influenciam as suas escolhas quando propõem o acesso das crianças à arte foi a suposição que me guiou para organizar um novo projeto/processo de pesquisa, desenvolvido no Doutorado em Educação da UFRGS, na linha de pesquisa Arte, Linguagem e Tecnologia, orientado pela professora Analice Dutra Pillar, coordenadora do GEARTE.

\section{Em terra estranha: águas a conhecer e marcas a inscrever e escrever}

A aprovação para fazer o doutorado na UFRGS demarcaria mais um deslocamento: o de cruzar o Brasil em busca de outro Rio Grande; não mais os rios do Norte e Nordeste que percorria com uma "relativa" tranquilidade, pois entendia os modos de funcionar em movimento, compartilhava saberes e práticas, dialogava com as diferenças, encontrando pontos de aproximação no que move os educadores que trabalham com crianças. Habitava, agora, um rio do sul. Trazia as leituras das publicações do GEARTE e a experiência de docência e pesquisa na UFRN. 
A pesquisa de Doutorado (2009-2013) teve como objetivo investigar a relação entre experiências estéticas e prática docente com linguagens artísticas, narradas em memoriais produzidos por professores da educação da infância, no Curso de Especialização em Ensino de Arte e Educação Física na Infância, desenvolvido pelo Paideia/UFRN. A abordagem do tema experiência estética solicitou o estabelecimento de interfaces entre aportes teóricos que envolviam diferentes campos de conhecimento, tais como Filosofia, Semiótica, Arte/Educação e Pedagogia. Tratase de uma pesquisa de natureza qualitativa em que a metodologia assumiu, como princípios e estratégias de análise, a semiótica discursiva e alguns pressupostos da pesquisa (auto)biográfica, referentes à produção de narrativas como experiência de formação. O corpus da pesquisa foi composto por cinco memoriais de formação. $\mathrm{Na}$ análise dos textos, busquei identificar como as experiências estéticas dos professores estavam presentes nos discursos que teciam sobre a sua prática. A produção de sentido na leitura das narrativas dos professores ocorreu a partir do estabelecimento de relações entre estética, arte, ensino e infância.

Acreditando na tese de que as experiências estéticas dos professores influenciam a elaboração de propostas de aprendizagem das linguagens artísticas para crianças, caminhei em busca das significações para o termo "experiência estética", tomando como referência os estudos de Dewey, Merleau-Ponty e Greimas sobre experiência estética. Tais autores se debruçaram sobre o conceito de experiência estética, considerando as relações que o sujeito estabelece em seu contato significativo no e com o mundo. A dimensão estética é colocada como parte da experiência vivida, ultrapassando o campo de abrangência da arte. Dewey (2010) aborda a experiência estética buscando relações entre pensar e agir. Merleau-Ponty (1991; 1999; 2004; 2012), ao enfocá-la, questiona a fragmentação entre corpo e mente. Greimas (2002) toma como referência a fenomenologia de Merleau-Ponty para inserir o sujeito em processos de significação estética e estésica. Para Dewey, a interação sujeito-mundo é relação basilar da produção de conhecimento. No processo do conhecer, a mente é a instância de mediação entre o homem e o mundo. Embora enfatize a atuação racional, isto é, a relação entre pensamento e experiência, Dewey 
não o faz colocando em oposição racionalidade e sensibilidade. Ele considera, como ponto de partida de suas reflexões sobre a experiência estética, o organismo total funcionando em seu ambiente. Nesse envolvimento com o mundo, o sujeito percebe as situações e age, a emoção tonaliza o que é vivenciado. Para Dewey, a dimensão estética está presente em experiências do cotidiano, entre elas as que se referem à arte. Em Dewey, encontramos referências sobre a importância da continuidade da experiência em direção a uma finalidade positiva como aquilo que lhe constitui como educativa e estética.

Merleau-Ponty, assim como Dewey, considera a estética como dimensão do mundo vivido, mas o faz enfatizando a importância da percepção e do corpo na relação sujeito-objeto. Assim, a experiência estética é abordada como interação entre sujeito e mundo, considerando que o sujeito é corpo reflexionante o qual produz sentidos para sua experiência no mundo e que se expressa por meio de linguagens. Merleau-Ponty nos conduz à compreensão da interação sujeito-objeto como o que torna a experiência significativa. Para ele, toda consciência é sempre consciência de alguma coisa; é ser no mundo produzindo-se e produzindo sentidos. A percepção é a experiência vivida corporalmente; a mente que percebe é uma mente encarnada. $O$ organismo que percebe está imbricado com o seu entorno. O sujeito é corpo que atua numa dimensão de espaço e tempo determinado. A consciência é uma região fenomenológica de mediação intencional em relação ao mundo, essa mediação é corporal e relacional. Merleau-Ponty questiona a oposição, colocada pela tradição filosófica, entre logos e estético. Logos relacionado à razão, e estético, relacionado ao sensível. O autor busca o que está entre essa suposta oposição para afirmar a presença de um logos estético na experiência do ser no mundo. Assim, a percepção estética é entendida como dimensão da experiência vivida.

Greimas (2002) busca, na fenomenologia de Merleau-Ponty, a noção de sujeito sensível incrustado no mundo, feito do mesmo estofo das coisas, carne do mundo, sujeito que pode experienciar o entorno como corpo reflexionante em uma relação estesiologica com aquilo que the desafia produzir sentido. Em Da Imperfeição (GREIMAS, 2002), ele traz excertos de texto literários para enfocar a dimensão PONTES, Gilvânia Maurício Dias de. Entre Rios Grandes, encontros estéticos significantes. 104 Revista GEARTE, Porto Alegre, v. 6, n. especial, p. 97-109, abr. 2019. 
sensível da significação, integrando às análises semióticas a problemática dos fenômenos de significação em sua dimensão estética.

As concepções de experiência estética, tecida pelos autores referidos, guiaram a busca pela relação entre experiências estéticas e práticas docentes, narradas em memoriais de formação. Nestes textos sobre práticas, projetos de vida e formação se entrelaçaram na produção de sentido para o vivido, o que aprontou para conclusões que indicaram que as experiências estéticas vivenciadas pelos professores, em ambientes formais e não formais, os constituíam como leitores da arte e da estética do seu entorno. Considerar o professor como sujeito capaz de produzir sentido para as linguagens artísticas e práticas docente, requer observar sua inserção no mundo como sujeito encarnado, corporalmente envolvido com o seu entorno e com a sua cultura, assim como um artífice de sua atuação docente.

\section{O fluxo corrente}

Finalizado o processo de Doutoramento, voltei para Natal e assumi uma sala com crianças, além das atividades de extensão nesse período configuradas pela docência nos módulos de Artes Visuais na Especialização em Docência na Educação Infantil e no Curso de Aperfeiçoamento em Artes na infância.

No início do ano letivo de 2013, assumo uma turma de $1^{\circ}$ ano do Ensino Fundamental, crianças entre seis e sete anos. Durante o ano, as crianças do grupo estiveram interessadas em desvendar os encantos da Cidade do Natal. Encantos como significante relacionado a encantamentos e encanto como busca de conhecimento sobre o seu canto. Os olhares das crianças sobre a Cidade do Natal foi o eixo organizador da prática docente ao longo dos quatro bimestres desse ano.

Tomamos como ponto de partida as minhas reflexões sobre experiência estética, presentes no trabalho de Doutorado (PONTES, 2013), para organizar as práticas docentes com as crianças. A experiência estética se dá no encontro com outros - sujeitos ou objetos. Um encontro que exige de nós a produção de sentido para aquilo com o qual nos deparamos. Esse sentido (significação) é, inicialmente, 
corporal, isto é, nós nos expomos e nos deixamos afetar porque nossa visão, olfato, tato e paladar, são acionados, como sistema, para captar/significar as "coisas do mundo". Dessa forma, a experiência estética é sensitiva, mas também vai além da sensação, quando somos levados a refletir sobre o que vivenciamos.

Um dos eixos do trabalho com o Tema de Pesquisa22 "Cidade de Natal" dizia respeito ao estudo dos aspetos culturais e artísticos de Natal. Para abordar tal eixo foi realizado, com as famílias, um levantamento dos produtores de arte, como resultado recebemos informações sobre atores, músicos, artistas plásticos, artesãos que tinham alguma relação com as famílias e crianças do grupo. Para organização da sequência didática para estudo do tema foram observados como princípios: a necessidade de propiciar o acesso das crianças a obra de artistas locais, brasileiros ou internacionais; o entendimento de que as crianças são atores do seu processo de aprendizagem, e ao professor cabe estar atento aos interesses e necessidades das mesmas, para descobrir temas que podem gerar experiências artísticas e estéticas. Dos artistas elencados pelas famílias e crianças, foram escolhidos alguns mais próximos das crianças para que fosse possível entrevistar e abordar sua produção artística e processo de criação com o grupo. Assim, foram convidados para entrevistas um pintor, uma cantora e uma cineasta natalenses. Ou seria melhor dizer, convidamos Edi Chá, pintor e tio de uma criança do grupo; Jussara Queiroz ${ }^{23}$, uma tia avó que foi cineasta na década de 1980 com filmes premiados nacionalmente, e teve a carreira bruscamente interrompida por um problema neurológico, que a fez perder a capacidade de falar. E a cantora Khrystal ${ }^{24}$, amiga da mãe de um dos meninos. Com

22 Metodologia de trabalho assumida pelo Núcleo de Educação da Infância, desde o final da década de 1980, o Tema de Pesquisa, é um tema de estudo que surge do interesse/necessidade das crianças e articula três dimensões do atendimento à infância: característico sócio culturais das crianças; peculiaridades do desenvolvimento infantil e saberes/fazeres de diferentes campos de conhecimento.

23 A cineasta Jussara Queiroz nasceu em 04 de janeiro de 1956 na cidade de Jucurutu/RN. Teve a carreira interrompida na década de 90 devido a problemas de saúde. Dentre suas obras, podemos citar: "Fora de ordem" (1982); "Acredito que o mundo será melhor" (1983); "Um caso de vida ou morte" (1895); "Um certo meio ambiente (1986); e "A árvore de Marcação" (1993). Disponível em: www.mulheresaudiovisual.com.br/jussara-queiroz. Acesso em: 09 dez. 2018.

24 Nasceu em Natal (RN) em 28 de maio de 1981 e aprendeu em casa a gostar de música. Aos 17 anos, já cantava em bares da cidade. Em 2004, começou uma pesquisa para um possível trabalho 
Edi Chá as crianças aprenderam a fazer aquarelas, com Khystal conheceram músicas de autoria da cantora e de outros artistas do RN. O encontro com Jussara Queiróz foi emocionante, as crianças aprenderam sobre cinema e sobre inclusão. Como a cineasta não consegue falar, a entrevista girou em torno das narrativas que as crianças teceram sobre ela, após se apropriarem de alguns fatos de sua vida e obra, que thes foram apresentados pelos professores com ajuda de informações fornecidas pela família da entrevistada. Jussara Queiroz ouviu o relato das crianças se mostrando emocionada com a entrevista às avessas.

No encontro entre esses produtores de arte e as crianças, arte e vida se entrelaçaram para que o processo criativo dos mesmos se tornasse significativo para todas as crianças do grupo. Os sentidos de uma cidade são criados, especialmente, pelos que nela vivem. Neste caso, crianças que se preocuparam em olhar mais atentamente para a sua cidade e, como desdobramento do tema, chegaram às produções das Artes Visuais, Música e Cinema que estavam muito próximas e com as quais puderam estabelecer diálogos profícuos.

A oportunidade de interação presencial com o artista é uma experiência estética impregnada de valores culturais e de conteúdos específicos das linguagens artísticas, que podem promover a ampliação do repertório de leitura e atuação das crianças. Mas, para que assim seja é necessário pensar a organização da sequência de situações pedagógicas que encadeiam os momentos que constituem a experiência. Organizar o passo a passo, isto é, as estratégias de aproximação das crianças ao mundo das artes é movimento de pesquisa em que teoria e prática não se separam, pois como ressalta Ferraz e Fusari (2009) é preciso saber arte e saber ser professor de arte. Acrescento a essa afirmação mais um componente, é preciso também saber ser professor de crianças. Conhecer as especificidades e demandas do trabalho com a infância no espaço escolar. Esse trabalho solicitou o estabelecimento de interfaces entre os aspectos históricos, geográficos, artísticos e culturais da cidade de Natal.

que resultou em show chamado "O Côco do Brasil" http://cddoistempos.wixsite.com/khrystal.material. Acesso em: 09 dez. 2018. 
Tais aspectos foram analisados e $(\mathrm{re})$ apresentados pelas crianças nas linguagens cênica, visuais, oral e escrita e, ao final de 2013, publicado no livro "Natal em cena: misturando arte, cultura e natureza da Noiva do Sol" (PONTES; CORDEIRO, 2013).

Durante os anos de retorno à terra Natal não me distanciei das atividades do GEARTE, participando de bancas de qualificação de mestrado e da Revista GEARTE. Mas, as interfaces entre docência, pesquisa e extensão na UFRN, durante os anos de 2016 e 2017, inspiraram o desejo de voltar a Rio do Sul, presencialmente, para realização do estágio de pós-doutorado sob a supervisão de Analice Dutra Pillar, em 2018, para realizar estudos sobre mediação em práticas docentes, a partir da análise de material documental produzido por professores e estudantes ao participarem das atividades da pesquisa "Artes Visuais e práticas docentes na Educação Infantil" e do projeto de extensão "Artes Visuais na Educação Infantil: processos de formação de mediadores na escola da infância", sob minha coordenação. A pesquisa, com objetivo de realizar a investigação de interfaces entre Artes Visuais, práticas docentes e Educação Infantil, foi construída tendo como um dos seus desdobramentos a inserção de estudantes dos cursos de Artes Visuais em Pedagogia em turmas de crianças, abordando como temática a linguagem fotográfica. Os estudos realizados durante o pós-doutorado enfatizam a análise do material produzido durante a intervenção, observando como foram organizados os processos de mediação e como se ocorreu a interação entre crianças e adultos para a produção de sentido sobre a fotografia. Mas, essa é outra história de cruzamentos entre os Rios Grandes que deixo para contar em outros textos.

\section{Referências}

BARBOSA, Ana Mae. Tópicos Utópicos. Belo Horizonte: C/Arte, 1998.

BARBOSA, Ana Mae. A imagem no ensino de Arte: anos 1980 e novos tempos. 7. ed. São Paulo: Perspectiva. 2009.

BARBOSA, Ana Mae. Redesenhando o desenho: educadores, política e história. São Paulo: Cortez, 2015.

DEWEY, John. Arte como experiência. Tradução Vera Ribeiro. São Paulo: Martins Fontes, 2010.

FERRAZ, Maria Heloisa de Toledo; FUSARI, Maria Felisminda de Resende. Metodologia do ensino de Arte: Fundamentos e proposições. 2. ed. São Paulo: Cortez, 2009. 
GREIMAS, Algirdas Julien. Da Imperfeição. São Paulo: Hacker Editores, 2002.

IAVELBERG, Rosa. O desenho cultivado na criança: práticas e formação de educadores. Porto Alegre: Zouk, 2006.

IAVELBERG, Rosa. Desenho na Educação Infantil. São Paulo: Melhoramentos, 2013.

MERLEAU-PONTY, Maurice. Signos. Tradução Maria Ermantina Galvão Gomes Pereira. São Paulo: Martins Fontes, 1991.

MERLEAU-PONTY, Maurice. Fenomenologia da Percepção. Tradução Carlos Alberto Ribeiro de Moura. São Paulo: Martins Fontes, 1999.

MERLEAU-PONTY, Maurice. O olho e o espírito. Tradução Paulo Neves e Maria Ermantina Gomes. São Paulo: Cosac \& Naify, 2004.

MERLEAU-PONTY, Maurice. A prosa do mundo. Tradução Paulo Neves. São Paulo: Cosac \& Naify, 2012.

PILLAR, Analice Dutra (org.). A educação do olhar no ensino das artes. Porto Alegre: Mediação, 1997.

PILLAR, Analice Dutra (org.). Desenho e escrita como sistema de representação. Porto Alegre: Penso, 2012.

PILLAR, Analice Dutra (org.). A educação do olhar no ensino da arte. In: BARBOSA, Ana Mae (org.). Inquietações e mudanças no ensino da arte. São Paulo: Cortez, 2002. p. 71-82.

PONTES, Gilvânia Maurício Dias de. A presença da arte na Educação Infantil: olhares e intenções. 2001. Dissertação - (Mestrado em Educação). Programa de Pós-Graduação em Educação, Universidade Federal do Rio Grande do Norte, Natal. 2001.

PONTES, Gilvânia Maurício Dias de. Arte na educação da infância: saberes e práticas da dimensão estética. 2013. Tese (Doutorado em Educação) - Programa de Pós-Graduação em Educação, Universidade Federal do Rio Grande do Sul, Porto Alegre. 2013.

PONTES, Gilvânia Maurício Dias de; CORDEIRO, Sandro Silva da (org.). Natal em cena: misturando arte, cultura e natureza da Noiva do Sol. Natal: EDUFRN, 2013.

RICHTER, Sandra. Criança e pintura: ação e paixão de conhecer. Porto Alegre: Mediação, 2005.

ROSSI, Maria Helena. Imagens que falam: leitura da arte na escola: Porto Alegre: Mediação, 2003.

\section{Gilvânia Maurício Dias de Pontes}

Realizou Estágio de Pós-Doutorado (2018-2019) na Universidade Federal do Rio Grande do Sul (UFRGS). Doutora em Educação pelo Programa de Pós-Graduação em Educação da UFRGS (2013). Mestre em Educação pela Universidade Federal do Rio Grande do Norte (2001). Especialista em Administração Educacional pela UFRN (1993). Graduada em Pedagogia pela Universidade Federal do Rio Grande do Norte (1990). Integrante do Grupo de Pesquisa em Educação e Arte (GEARTE/ UFRGS/CNPq). Professora Titular da Universidade Federal do Rio Grande do Norte, Lotada no Núcleo de Educação da Infância do Colégio de Aplicação- NEI/CAp/UFRN.

E-mail: gilvaniapontes@hotmail.com

Currículo Lattes: http://lattes.cnpq.br/2536072255193237

Recebido em 10 de dezembro de 2018

Aceito em 18 de fevereiro de 2019 